\title{
Delayed bilateral obturator nerve injury due to compressing bilateral pelvic lymphoceles after robot-assisted laparoscopic radical prostatectomy and bilateral lymphadenectomy for prostatic carcinoma
}

\author{
Ayman Aljomaa
}

Clinic for General, Visceral, Thoracic and Vascular Surgery, Klinikum Bremerhaven-Reinkenheide. Postbrookstraße 103, Bremerhaven, Germany

\begin{tabular}{|c|}
\hline Access this article online \\
\hline Website: www.avicennajmed.com \\
\hline DOI: 10.4103/ajm.AJM_215_17 \\
\hline Quick Response Code: \\
\hline
\end{tabular}

\begin{abstract}
A clinically significant obturator nerve injury is uncommon after robot-assisted radical prostatectomy and lymphadenectomy. If the injury is due to a direct intraoperative event such as transection or stretching of the nerve, the patients present typically in the immediate postoperative period. On the other hand, an indirect injury through compression of the nerve through a pelvic fluid collection (hematoma or lymphocele) progresses insidiously and delays the presentation of these patients making a dilemma in recognizing these patients and differentiating them from those with other causes of neurological deficits. A delay in the correct management of the compressing collections may negatively affect the neurological function of the patient. We demonstrate a 61 -year-old male who presented with pain and motor weakness of obturator origin 1 week after robot-assisted radical prostatectomy and lymphadenectomy for prostatic cancer. The computed tomography scan showed bilateral pelvic lymphoceles possibly compressing the obturator nerves. The neurological function has improved after evacuation of these collections. This case emphasizes the importance of considering delayed postsurgical compression of the obturator nerve in our differential diagnosis when patients present with typical signs and symptoms of obturator nerve injury after robot-assisted radical prostatectomy and lymphadenectomy. Early diagnosis and evacuation of these collections would improve the neurological outcome.
\end{abstract}

Key words: Lymphadenectomy, lymphocele, obturator, prostatectomy, robot-assisted

\section{INTRODUCTION}

Postoperative obturator nerve injury is uncommon after robot-assisted radical prostatectomy and lymphadenectomy. The injury of the nerve may be due to stretching, transection, or compression. These patients typically present with sensory deficit in the upper medial thigh, neuropathic pain in the groin and upper medial thigh, and motor weakness in the thigh flexion and adduction. The majority

Address for correspondence: Dr. Ayman Aljomaa,

Clinic for General, Visceral, Thoracic and Vascular Surgery, Klinikum Bremerhaven-Reinkenheide. Kirchenstraße 9, 27568 Bremerhaven,

Germany.

E-mail: dr.ayman.m.aljomaa1989@gmail.com of postoperative injuries may resolve within a few weeks unless complete transection has occurred. In the case of nerve compression through a pelvic fluid collection, an early evacuation is the cornerstone of the management

This is an open access journal, and articles are distributed under the terms of the Creative Commons Attribution-NonCommercial-ShareAlike 4.0 License, which allows others to remix, tweak, and build upon the work non-commercially, as long as appropriate credit is given and the new creations are licensed under the identical terms.

For reprints contact: reprints@medknow.com

Cite this article as: Aljomaa A. Delayed bilateral obturator nerve injury due to compressing bilateral pelvic lymphoceles after robot-assisted radical prostatectomy and bilateral lymphadenectomy for prostatic carcinoma. Avicenna J Med 2018;8:107-9. 


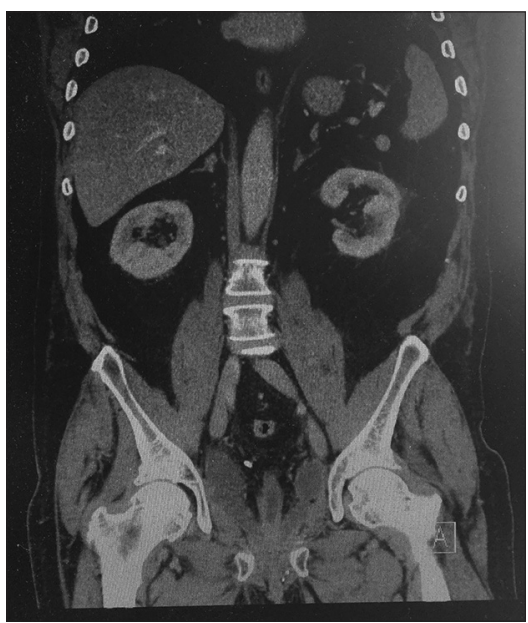

Figure 1: Computed tomography scan showing bilateral pelvic lymphoceles in the obturator fossae (coronal image)

to relief symptoms. We describe a case of postoperative obturator injury secondary to postoperative compressing bilateral pelvic lymphoceles.

\section{CASE REPORT}

A 61-year-old male with a clinical stage T2c prostatic carcinoma underwent an uncomplicated robot-assisted radical prostatectomy with bilateral dissection of the obturator and iliac lymph nodes. In the $1^{\text {st }}$ postoperative week, the patient recovered well from the surgery and was discharged home. One the day after discharge, he complained of bilateral groin and thigh discomfort. These complaints have worsened over the day, so that he decided to seek medical care. The patient presented in an urological emergency department. Since there was no documented obturator nerve injury in the operation report and in the short postoperative period, it was initially postulated that these complaints are not due to a postoperative complication. The patient was reassured and discharged with pain medications. However, the patient continued to have complaints, the ability to walk has worsened in the next few days, and he presented in our general surgical emergency department after another 1 week. It has been noted that the patient demonstrated bilateral proximal leg weakness and an inability to flex and adduct his thighs. Because of this clinical scenario, a computed tomography (CT) scan of the abdomen and pelvis was performed, which showed bilateral hypodense collections directly medial to the internal obturator muscles with a thin membrane $(3 \mathrm{~cm} \times 5 \mathrm{~cm}$ [right], $4 \mathrm{~cm} \times 4.5 \mathrm{~cm}$ [left]). See figures 1 and 2 . This finding was consistent with large postoperative lymphoceles involving the obturator fossa bilaterally. Neurology was consulted and agreed with the diagnosis of obturator nerve compression. A percutaneous drainage was indicated. Clear fluid was evacuated from the

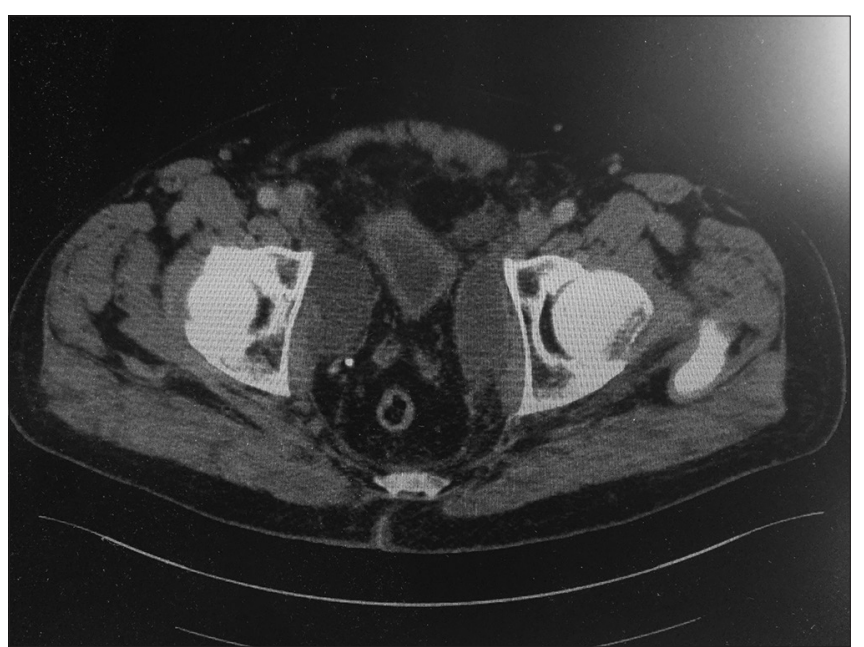

Figure 2: Computed tomography scan showing bilateral pelvic lymphoceles in the obturator fossae (axial image)

bilateral obturator fossae. The patient had an immediate improvement in his neurologic symptoms, regaining his normal motor strength within few weeks.

\section{DISCUSSION}

Obturator nerve injuries are serious complications after robot-assisted radical prostatectomy and lymphadenectomy and may affect the neurological outcome. Clinicians usually attribute most neuropathies present in the late postoperative period not to postoperative complications. This resulted in a delay in the diagnosis and management in our case because our patient developed signs of obturator neurapraxia firstly 1 week after surgery. CT scan showed bilateral pelvic collections, indicative of bilateral deep pelvic lymphoceles compressing the obturator nerves. After the pelvic lymphoceles were evacuated, the patient regained his lower motor and sensory functions. A prospective cohort study of 521 patients who underwent a robot-assisted radical prostatectomy and extended lymphadenectomy for prostatic cancer showed a $2.5 \%$ incidence of postsurgical symptomatic pelvic lymphoceles. ${ }^{[1]}$

An important risk factor that may contribute to the formation of the postsurgical lymphoceles is the disruption of lymphatics which occurs with the more extended lymphadenectomy and in the case of nonjudicious use of electrocautery in the dissection. Other less important risk factors are the neoadjuvant radiotherapy and the application of subcutaneous heparin. ${ }^{[2]}$ Several studies compared open, laparoscopic, and robot-assisted prostatectomy and lymphadenectomy regarding the incidence of postsurgical lymphocele. In one study, symptomatic postsurgical lymphoceles were found in $2.3 \%$ of open prostatectomy and lymphadenectomy patients and in none of laparoscopic prostatectomy and 
lymphadenectomy patients. ${ }^{[3]}$ Another comparison of open and robot-assisted prostatectomy and lymphadenectomy found no difference in the incidence rate of symptomatic lymphoceles, including $2.5 \%$ and $2 \%$, respectively. ${ }^{[4]}$

Two studies comparing laparoscopic versus robot-assisted prostatectomy and lymphadenectomy showed an incidence of postsurgical lymphoceles of $0.15 \%$ and $0.13 \%$, respectively. ${ }^{[5,6]}$

\section{CONCLUSION}

Although uncommon, delayed neurologic complications after robot-assisted radical prostatectomy and lymphadenectomy could be a result of insidious postoperative fluid collections. Postoperative collections compressing the obturator nerve should immediately be recognized and evacuated to improve the neurological outcome.

\section{Declaration of patient consent}

The authors certify that they have obtained all appropriate patient consent forms. In the form the patient(s) has/have given his/her/their consent for his/her/their images and other clinical information to be reported in the journal. The patients understand that their names and initials will not be published and due efforts will be made to conceal their identity, but anonymity cannot be guaranteed.

\section{Financial support and sponsorship}

Nil.

\section{Conflicts of interest}

There are no conflicts of interest.

\section{REFERENCES}

1. Keskin MS, Argun ÖB, Öbek C, Tufek I, Tuna MB, Mourmouris P, et al. The incidence and sequela of lymphocele formation after robot-assisted extended pelvic lymph node dissection. BJU Int 2016;118:127-31.

2. Loeb S, Partin AW, Schaeffer EM. Complications of pelvic lymphadenectomy: Do the risks outweigh the benefits? Rev Urol 2010;12:20-4.

3. Solberg A, Angelsen A, Bergan U, Haugen OA, Viset T, Klepp O, et al. Frequency of lymphoceles after open and laparoscopic pelvic lymph node dissection in patients with prostate cancer. Scand J Urol Nephrol 2003;37:218-21.

4. Zorn KC, Katz MH, Bernstein A, Shikanov SA, Brendler CB, Zagaja GP, et al. Pelvic lymphadenectomy during robot-assisted radical prostatectomy: Assessing nodal yield, perioperative outcomes, and complications. Urology 2009;74:296-302.

5. Patel VR, Palmer KJ, Coughlin G, Samavedi S. Robot-assisted laparoscopic radical prostatectomy: Perioperative outcomes of 1500 cases. J Endourol 2008;22:2299-305.

6. Guillonneau B, Rozet F, Cathelineau X, Lay F, Barret E, Doublet JD, et al. Perioperative complications of laparoscopic radical prostatectomy: The montsouris 3-year experience. J Urol 2002;167:51-6. 